\title{
PENGARUH ANIMASI BERGERAK TERHADAP PEMAHAMAN KONSEP MATEMATIKA SISWA KELAS XII DI SMAN 1 LANGSA
}

\author{
Hanani Azzahra ${ }^{1}$ Mazlan $^{2}$, M. Zaiyar ${ }^{3}$ \\ 1.2.3 Institut Agama Islam Negeri Langsa, Jalan Meurandeh, Langsa 24411, Indonesia \\ Email: hanani1102@gmail.com \\ Email: mazlan@iainlangsa.ac.id \\ Email: m.zaiyar@iainlangsa.ac.id
}

\begin{abstract}
Abstrak
Pemahaman konsep merupakan suatu kemampuan yang sangat penting dalam pembelajaran matematika. Dengan kemampuan pemahaman konsep siswa akan mampu memanfaatkan atau mengaplikasikan apa yang telah dipahaminya serta mengungkapkannya kembali dengan makna yang sama dalam kegiatan belajar. Tujuan dalam penelitian ini adalah untuk mengetahui apakah animasi bergerak dengan berbantuan software Cabri $3 D$ berpengaruh terhadap pemahaman konsep matematika siswa pada materi dimensi tiga. Penelitian ini dilaksanakan di SMAN 1 Langsa tahun ajaran 2019/2020. Penelitian ini termasuk dalam jenis penelitian kuantitatif dengan desain One Group Pretest-Posttest Design. Populasi dalam penelitian ini adalah seluruh siswa kelas XII SMA Negeri 1 Langsa sebanyak 317 orang yang terdiri dari 10 kelas, sedangkan sampelnya adalah siswa kelas XII MIA-8 dengan jumlah siswa 32 orang. Hasil penelitian menunjukkan bahwa $t_{\text {hitung }}=22,88$ dan $\mathrm{t}_{\text {tabel }}=1,696$ maka $\mathrm{t}_{\text {hitung }}>\mathrm{t}_{\text {tabel }}$ yaitu 22,88 $>1,696$ sehingga diperoleh $\mathrm{H}_{0}$ ditolak dan $\mathrm{H}_{\mathrm{a}}$ diterima. Dengan demikian dapat disimpulkan bahwa terdapat pengaruh animasi bergerak terhadap pemahaman konsep matematika siswa kelas XII di SMA Negeri 1 Langsa.
\end{abstract}

Kata kunci: Animasi Bergerak, Pemahaman Konsep Matematika

\begin{abstract}
Understanding the concept is a very important ability in learning mathematics. With the ability to understand concepts, students will be able to use or apply what they have understood and express it again with the same meaning in learning activities. The purpose of this study was to see whether moving animation assisted by Cabri 3D software had an effect on students' understanding of mathematical concepts in three-dimensional material. This research was conducted at SMAN 1 Langsa for the 2019/2020 school year. This research is included in the type of quantitative research with the design of One Group Pretest-Posttest Design. The population in this study were all students of class XII SMA Negeri 1 Langsa as many as 317 people consisting of 10 classes, while the sample was students of class XII MIA-8 with 32 students. The results showed that $\mathrm{t}_{\text {count }}=22.88$ and $\mathrm{t}_{\text {table }}=1.696$, then $\mathrm{t}_{\text {count }}>\mathrm{t}_{\text {table, }}$ namely $22.88>1.696$ so that $\mathrm{H}_{0}$ is rejected and $\mathrm{H}_{\mathrm{a}}$ is accepted. Thus it can be ignored that there is an effect of moving animation on understanding the mathematical concepts of class XII students at SMA Negeri 1 Langsa.
\end{abstract}

Keywords: Moving Animation, Understanding Mathematical Concepts

\section{PENDAHULUAN}

Pemahaman merupakan salah satu tujuan pembelajaran yang sangat penting dalam proses pembelajaran, termasuk pemahaman siswa terhadap pelajaran matematika. Kesulitan siswa untuk memahami materi yang disampaikan Guru akan sangat berpengaruh pada proses pembelajaran terutama pelajaran Matematika. Menurut Sundayana (2013) matematika merupakan salah satu komponen dari beragam mata pelajaran yang mempunyai peran penting khususnya dalam pendidikan. 
Namun sampai saat ini masih banyak siswa yang menganggap matematika sebagai mata pelajaran yang sulit, tidak menyenangkan dan menjadi momok dalam pembelajaran. Ruseffendi (2006) menyatakan bahwa sebagian besar siswa mengalami kesulitan dalam pembelajaran matematika seperti pada materi yang sederhana, bahkan terjadi kesalahan dalam memahami konsep setelah belajar matematika. Hal ini membuktikan bahwa banyak anak yang mengalami kesulitan belajar matematika disebabkan mereka bukan memahami konsepnya melainkan hanya menghafalnya, sehingga dalam menerapkan suatu konsep matematika, mereka tidak dapat menerapkannya baik dalam menyelesaikan masalah dalam mata pelajaran matematika maupun masalah dalam kehidupan sehari-hari.

Selain meningkatkan pemahaman siswa dalam pembelajaran matematika, guru juga diharapkan mampu untuk mengoptimalkan kemampuannya guna meningkatkan kemampuan siswa dalam memahami konsep matematika melalui penggunaan media atau model pembelajaran yang lebih bervariasi untuk menyampaikan materi dan konsep dalam memecahkan suatu masalah. Berdasarkan hasil observasi, diketahui masih banyak kegiatan pembelajaran yang dilakukan dengan cara konvensional sehingga siswa mudah bosan dalam mengikuti pelajaran walaupun perangkat multimedia tersedia dengan lengkap di kelas. Hal ini dapat dilihat dari pemahaman konsep yang masih kurang dalam materi matematika yang menyebabkan hasil belajar matematika siswa rendah jika dibandingkan dengan pelajaran yang lain.

Menurut Pratiwi (2016) kemampuan pemahaman konsep peserta didik dapat dilihat pada kemampuan peserta didik dalam menemukan, menjelaskan, menerjemahkan dan menyimpulkan suatu konsep matematika berdasarkan kemampuannya sendiri, bukan hanya sekedar menghafal. Menurut Kartika (2018) indikator-indikator yang menunjukkan pemahaman konsep antara lain:

1) Menyatakan ulang sebuah konsep.

2) Memberikan contoh dan bukan contoh dari suatu konsep.

3) Mengklarifikasikan objek menurut sifat-sifat tertentu sesuai dengan konsepnya.

4) Menyajikan konsep dalam berbagai bentuk representasi matematis.

5) Mengembangkan syarat perlu atau syarat cukup suatu konsep.

6) Menggunakan, memanfaatkan dan memilih prosedur atau operasi tertentu.

7) Mengaplikasikan konsep atau algoritma pada pemecahan masalah

Salah satu cara untuk meningkatkan kemampuan pemahaman konsep matematika siswa dapat ditempuh dengan penggunaan media pembelajaran. Penggunaan media pembelajaran matematika diperlukan agar siswa mempunyai pengalaman belajar yang lebih menarik dan bervariasi dalam pembelajaran matematika. Beberapa software yang dapat digunakan sebagai media pembelajaran matematika antara lain seperti Geogebra, Autograph, Cabri 3D, Maple, Carmetal, dan Geometer's Sketchpad. Adapun software yang digunakan dalam penelitian ini adalah program Cabri $3 D$. Program Cabri $3 D$ selain mudah dipahami dan digunakan, juga memiliki tampilan yang menarik sehingga dapat menarik minat siswa dalam pembelajaran.

Animasi memiliki daya tarik utama dalam sebuah program multimedia interaktif. Menurut Akhmaluddin (2013) animasi merupakan rangkaian atau sekumpulan gambar yang disusun secara berurutan dan di tampilkan pada tenggat waktu tertentu sehingga tercipta sebuah ilusi gambar bergerak. Efek animasi dalam pembelajaran selain digunakan untuk mendorong siswa agar termotivasi untuk belajar, namun juga memudahkan proses penyampaian materi yang dapat membantu siswa untuk lebih cepat. Animasi dalam software Cabri $3 D$ ialah perubahan posisi bangun ruang yang dapat berputar sehingga siswa dapat melihat seluruh bagian dari bangun tersebut yang juga dilengkapi dengan efek warna yang dapat diganti sesuai keinginan untuk lebih memperjelas materi yang disampaikan. Akibatnya hal ini dapat meningkatkan pemahaman konsep siswa terhadap materi dimensi tiga khususnya pada materi jarak dalam ruang. 


\section{METODE PENELITIAN}

Penelitian ini menggunakan metode eksperimen yaitu dengan adanya perlakuan kepada objek penelitian. Jenis penelitian ini adalah penelitian kuantitatif yang prosesnya dengan cara mengumpulkan data sebagai alat menemukan keterangan tentang apa yang ingin diketahui. Desain penelitian yang digunakan adalah One Group Pretest-Posttest Design yaitu tes yang diberikan dengan tujuan agar mengetahui perbedaan kemampuan pemahaman konsep matematika siswa antara sesudah dan sebelum menggunakan Animasi Bergerak. Penelitian ini dilakukan di SMA Negeri 1 Langsa yang tahun ajaran 2019/2020 dengan sampel penelitian adalah kelas XII sebanyak 1 kelas.

Teknik pengumpulan data yang digunakan dalam penelitian ini yaitu berupa tes. Tes yang dilakukan dengan menggunakan seperangkat tes yang memuat soal-soal mengenai materi dimensi tiga yaitu pada pembahasan bangun ruang kubus yang berjumlah 5 soal berbentuk uraian yang dirancang berdasarkan indikator pemahaman konsep. Kisi-kisi instrumen yang digunakan dalam penelitian ini dapat dilihat pada tabel berikut ini :

Tabel 1. Kisi-kisi Instrumen Tes

\begin{tabular}{|c|c|c|c|c|}
\hline \multicolumn{2}{|r|}{ Kompetensi Dasar } & $\begin{array}{c}\text { Indikator } \\
\text { Pembelajaran }\end{array}$ & $\begin{array}{l}\text { Indikator Pemahaman } \\
\text { Konsep }\end{array}$ & $\begin{array}{c}\text { Nomor } \\
\text { Soal }\end{array}$ \\
\hline \multirow{3}{*}{\multicolumn{2}{|c|}{$\begin{array}{l}3.2 \text { Mendeskripsikan } \\
\text { jarak dalam ruang } \\
\text { (antar titik, titik ke } \\
\text { garis dan titik ke } \\
\text { bidang) }\end{array}$}} & 1. Menentukan jarak & \multirow{3}{*}{$\begin{array}{l}\text { 1. Mengklarifikasikan objek } \\
\text { menurut sifat-sifat tertentu } \\
\text { sesuai dengan konsepnya. } \\
\text { 2. Menyajikan konsep dalam } \\
\text { berbagai bentuk } \\
\text { representasi matematika }\end{array}$} & 1,2 \\
\hline & & antara dua titik & & \\
\hline & & $\begin{array}{l}\text { 2. Menentukan jarak } \\
\text { dari titik ke garis }\end{array}$ & & 3,4 \\
\hline \multicolumn{2}{|c|}{$\begin{array}{l}\text { Menentukan jarak } \\
\text { dalam ruang (antar } \\
\text { titik, titik ke garis } \\
\text { dan titik ke bidang) }\end{array}$} & $\begin{array}{l}\text { 3. Menentukan jarak } \\
\text { dari titik ke bidang }\end{array}$ & $\begin{array}{l}\text { 3. Menggunakan, } \\
\text { memanfaatkan dan } \\
\text { memilih prosedur atau } \\
\text { operasi tertentu. } \\
\text { 4. Mengaplikasikan konsep/ } \\
\text { algoritma pada pemecahan } \\
\text { masalah }\end{array}$ & 5 \\
\hline
\end{tabular}

Diadopsi dari Diah Rahmawati (2011)

Kriteria penskoran yang digunakan dalam penelitian ini adalah adalah kriteria penskoran menurut Susilawati, yaitu:

Tabel 2. Pedoman Penskoran Pemahaman Konsep Matematika

\begin{tabular}{|c|l|c|}
\hline Tingkat Pemahaman & \multicolumn{1}{|c|}{ Kriteria } & Skor \\
\hline Tidak Paham & Tidak menjawab sama sekali & 0 \\
\hline Miskonsepsi & $\begin{array}{l}\text { Ada menjawab, tapi perhitungan dan konsep yang } \\
\text { digunakan salah. }\end{array}$ & 1 \\
\hline Miskonsepsi Sebagian & $\begin{array}{l}\text { Jawaban memberikan sebagian informasi yang benar, } \\
\text { tapi menunjukkan adanya kesalahan konsep dalam } \\
\text { menjelaskan. }\end{array}$ & 2 \\
\hline Paham Sebagian & $\begin{array}{l}\text { Jawaban hampir benar dan mengandung sebagian } \\
\text { konsep, tapi ada sedikit kesalahan perhitungan. }\end{array}$ & 3 \\
\hline Paham Seluruhnya & $\begin{array}{l}\text { Jawaban benar dan mengandung seluruh konsep serta } \\
\text { membuat kesimpulan. }\end{array}$ & 4 \\
\hline
\end{tabular}

Diadopsi dari Ningrum Widianingsih dan Yenni (2016) 


\section{HASIL PENELITIAN DAN PEMBAHASAN}

Berdasarkan tes yang telah diberikan pada siswa kelas XII SMAN 1 Langsa dengan menggunakan animasi bergerak berbantuan software Cabri 3D, diperoleh data sebagai berikut:

Tabel 3. Perbandingan Nilai Hasil Pre-test dan Post-test

\begin{tabular}{|c|c|c|}
\hline Statistik & Pre-test & Post-test \\
\hline Jumlah Siswa & 32 & 32 \\
\hline Nilai terendah & 20 & 35 \\
\hline Nilai tertinggi & 85 & 100 \\
\hline Mean & 35,41 & 57,75 \\
\hline Median & 40 & 80 \\
\hline Modus & 26,25 & 61,25 \\
\hline Varians & 241,6 & 203,87 \\
\hline Standar Deviasi & 15,54 & 14,28 \\
\hline
\end{tabular}

Dari data pada tabel di atas dapat dilihat bahwa perolehan nilai post-test setelah diberikan perlakuan mengalami peningkatan dibandingkan nilai pre-test sebelum diberi perlakuan. Nilai rata-rata post-test lebih tinggi dibandingkan nilai pre-test dengan selisih 22,34. Begitu juga dengan median dan modus post-test yang mengalami peningkatan dibandingkan pada pre-test. Hal ini menunjukkan hasil pembelajaran dengan menggunakan animasi bergerak pada materi jarak dalam ruang berpengaruh terhadap pemahaman konsep siswa. Sedangkan hasil perhitungan uji hipotesis dapat dilihat pada tabel berikut ini:

Tabel 4. Hasil Uji Hipotesis

\begin{tabular}{|c|c|c|c|c|c|c|}
\hline \multirow{2}{*}{ n } & \multirow{2}{*}{$(\overline{\boldsymbol{x}})$} & \multirow{2}{*}{$\mathbf{S}^{2}$} & \multirow{2}{*}{$\begin{array}{c}\text { Taraf } \\
\text { signifikansi }\end{array}$} & \multicolumn{2}{|c|}{ Nilai t } & \multirow{2}{*}{ Kesimpulan } \\
\hline & & & & $\mathbf{t}_{\text {hitung }}$ & $\mathbf{t}_{\text {tabel }}$ & \\
\hline 32 & 57,75 & 14,278 & 0,05 & 22,88 & 1,696 & $\begin{array}{c}\mathrm{H}_{0} \text { ditolak } \mathrm{H}_{\mathrm{a}} \\
\text { diterima }\end{array}$ \\
\hline
\end{tabular}

Berdasarkan tabel diatas diperoleh hasil pengujian hipotesis daripada taraf signifikan $(\alpha)=0,05$ dan derajat kebebasan $(\mathrm{dk}=\mathrm{n}-1)$ dimana $\mathrm{dk}=32-1=31$ dengan kriteria pengujian distribusi $\mathrm{t}$ maka di dapatkan $t_{\text {hitung }}>t_{\text {tabel }}$ yaitu 22,88 $>1,696$ sehingga $\mathrm{H}_{0}$ ditolak dan $\mathrm{H}_{\mathrm{a}}$ diterima. Maka dapat disimpulkan bahwa terdapat pengaruh animasi bergerak terhadap pemahaman konsep matematika siswa kelas XII di SMA Negeri 1 Langsa. Sedangkan persentase besarnya pengaruh animasi bergerak dengan berbantuan software Cabri $3 D$ terhadap kemampuan pemahaman konsep matematika siswa didapatkan sebesar 67,4\% yang diperoleh dari perhitungan analisis regresi dengan bantuan SPSS 16.0

Dari analisis soal tes didapatkan bahwa nilai post-test siswa lebih tinggi dari pada pre-test. Siswa mampu menyelesaikan soal materi kubus yang diberikan dengan baik dan memenuhi indikator pemahaman konsep. Hal ini dapat dilihat pada pencapaian setiap indikator yang diperoleh siswa, yaitu pada indikator pertama siswa dapat menunjukkan dan menuliskan informasi dari masalah sesuai dengan konsepnya. Kemudian pada indikator yang kedua, siswa dapat menuliskan informasi yang sudah diperoleh ke dalam bentuk gambar sesuai dengan konsep yang telah dipelajari. Pada indikator yang ketiga, siswa dapat menuliskan rencana penyelesaian masalah dengan memilih rumus atau operasi tertentu yang sesuai dengan konsep dan informasi yang didapatkan. Dan pada indikator keempat, siswa mampu meyelesaikan masalah sesuai dengan tahapan pemecahan masalah.

Proses pembelajaran dengan menggunakan Cabri $3 D$ pada materi dimensi tiga, memberikan kesempatan kepada siswa untuk lebih aktif dan mengonstruksi pengetahuan yang didapatkannya sehingga hal tersebut dapat meningkatkan pemahaman konsep matematika siswa. Animasi bergerak pada software ini selain memudahkan siswa untuk melihat bangun ruang dari segala sisi serta memiliki 
tampilan yang menarik, juga dapat digunakan dengan mudah oleh siswa, dengan begitu siswa dapat termotivasi dalam melakukan pembelajaran.

\section{KESIMPULAN}

Berdasarkan hasil pembahasan di atas, maka dapat disimpulkan bahwa dari hasil perhitungan persentase animasi bergerak dengan berbantuan software Cabri $3 D$ berpengaruh terhadap kemampuan pemahaman konsep matematika siswa sebesar 67,4\%. Dan dari analisis data diperoleh hasil bahwa $t_{\text {hitung }}=22,88$ dan $t_{\text {tabel }}=1,696$ maka $t_{\text {hitung }}>t_{\text {tabel }}$ yaitu 22,88 $>1,696$ sehingga diperoleh $H_{0}$ ditolak dan $\mathrm{H}_{\mathrm{a}}$ diterima. Dengan demikian dapat disimpulkan bahwa terdapat pengaruh animasi bergerak terhadap pemahaman konsep matematika siswa kelas XII di SMA Negeri 1 Langsa.

\section{REFERENCES}

Akhirmi, A \& Mahmudi, A. (2015). Pengaruh Pemanfaatan Cabri 3D dan Geogebra pada Pembelajaran Geometri Ditinjau dari Hasil Belajar dan Motivasi. Jurnal Pendidikan Matematika dan Sains, III(2): 91-100.

Akhmaluddin. (2013). Analisis Perancangan Animasi Interaktif Pembelajaran Anatomi Otak Manusia Tingkat Sekolah Menengah Pertama. Techno Nusa Mandiri, X(2): 2.

Ananda, R dan Fadhli, M. (2018). Statistik Pendidikan (Teori dan Praktik Dalam Pendidikan. Medan: CV. Widya Puspita.

Azhar, Arsyad. (2010). Media Pembelajaran. Jakarta: Rajawali Pers.

Bagiyono. (2017). Analisis Tingkat Kesukaran dan Daya Pembeda Butir Soal Ujian Pelatihan Radiografi Tingkat 1. Pusdiklat, 16(1): 3-5.

Binanto, Iwan. (2010). Multimedia Digital - Dasar Teori dan Pengembangannya. Yogyakarta: Andi.

Hairunnisa AK. (2018). Efektivitas Penggunaan Software Cabri 3D dalam Pembelajaran Matematika pada Topik Geometri di Kelas XII SMAN 15 Makassar. (Skripsi, FKIP: Universitas Muhammadiyah Makassar).

Hamalik, Oemar. (2008). Perencanaan Pengajaran Berdasarkan Pendekatan Sistem. Jakarta: Bumi Aksara.

Hardini, dkk. (2012). Strategi Pembelajaran Terpadu. Yogyakarta: Familia.

Kartika, Yuni. (2018). Analisis Kemampuan Pemahaman Konsep Matematis Peserta Didik Kelas VII SMP pada Materi Bentuk Aljabar. Jurnal Pendidikan Tambusai, 2(4): 777-785.

Kurniadi, A.R. (2017). Pengaruh Metode Problem Solving Terhadap Kemampuan Berpikir Kreatif Matematis Siswa pada Materi Luas Bangun Datar. (Skripsi, FITK:UIN Syarif Hidayatullah Jakarta).

Lestari, E.K., \& Yudhanegara, M.R. (2015). Penelitian Pendidikan Matematika. Bandung: PT Refika Aditama.

Maulana, Ilham. dkk. (2017). Pengaruh Penggunaan Software Cabri 3D Terhadap Minat dan Hasil Belajar Matematika pada Pokok Bahasan Bangun Ruang. Tadris Matematika IAIN Syekh Nurjati Cirebon. ITEJ (Information Technology Engineering Journals).

Munir. (2012). Multimedia Konsep \& aplikasi dalam pendidikan. Bandung: Alfabeta.

Novitasari, Dian. (2016). Pengaruh Penggunaan Multimedia Interaktif terhadap Kemampuan Pemahaman Konsep Matematis Siswa. Universitas Muhammadiyah Tangerang. FIBONACCI Jurnal Pendidikan Matematika \& Matematika, 2(2): 8-18.

Pratiwi, D.D. (2016). Pembelajaran Learning Cycle 5E Berbantuan Geogebra Terhadap Kemampuan Pemahaman Konsep Matematis. Al-Jabar: Jurnal Pendidikan Matematika, 7(2): 191-202. 
Rahman, Chayriza. (2015). Perancangan Simulasi Animasi 2D Tata Cara Pemberian Suara pada Pemilihan Umum Menggunakan Metode Rotoscoping (Studi Kasus: Komisi Pemilihan Umum Kabupaten Deli Serdang). Pelita Informatika Budi Dharma, IX(1): 25-26.

Rahmawati, D. (2011). Keefektifan Pembelajaran Model Learning Cycle 5E (LC5E) Berbantuan Software Cabri $3 D$ dan Lembar Kerja Peserta Didik (LKPD) terhadap Kemampuan Pemahaman Konsep Peserta Didik Kelas X SMA Negeri 2 Pemalang pada Materi Dimensi Tiga. (Skripsi, FMIPA: Universitas Negeri Semarang).

Ruseffendi, E. T. (2006). Pengantar kepada Membantu Guru Mengembangkan Kompetensinya dalam Pengajaran Matematika untuk Meningkatkan CBSA. Bandung: Tarsito.

Rusmana, I.M \& Isnaningrum, I. (2014). Efektivitas Penggunaan Media ICT dalam Peningkatan Pemahaman Konsep Matematika. Fakultas Teknik, Matematika dan IPA Universitas Indrapasta PGRI Jakarta. Jurnal Formatif, 2(3): 198-205.

Sanjaya, Wina. (2008). Kurikulum dan Pembelajaran Teori dan Praktek Pengembangan KTSP. Jakarta: Kencana.

Sardiman. (2010). Interaksi \& Motivasi Belajar Mengajar. Jakarta: Rajawali Pers.

Sugiyono. (2015). Metode Penelitian pendidikan (Pendekatan Kuantitatif, Kualitatif, dan R\&D). Bandung: ALFABETA.

Sundayana, Rostina. (2013). Media Pembelajaran (untuk Guru, calon Guru, orang tua, dan para pecinta matematika. Bandung: ALFABETA.

Umbara, Uba. (2017). Implikasi Teori Belajar Konstruktivisme dalam Pembelajaran Matematika. Jurnal Matematika Ilmiah STKIP Muhammadiyah Kuningan (JUMLAHKU), 3(1): 31-38.

Widianingsih, N \& Yenni. (2016). Perbandingan Kemampuan Pemahaman Konsep Matematis Siswa Antara yang Mendapat Model Pembelajaran Course Review Horay dan Numbered Head Together. JPPM, 9(1): 116-123.

Winkel. (2004). Psikologi Pengajaran. Yogyakarta: Media Abdi. 